be caused by the persistence of a left fifth aortic arch, of the systemic-to-pulmonary type, ${ }^{2}$ associated with atresia of the pulmonary trunk and non-development of the proximal portion of the left sixth arch as shown in the diagram (fig 1). We have in our collection a specimen of what appears to be an identical condition. This was sent to us by Dr Michael Kearney of Tromso, Norway. It has been described elsewhere ${ }^{3}$ as a persistent fifth arch (fig 2). Persistence of the fifth arch is not as rare as is generally thought and can often mimic other arterial anomalies. ${ }^{4}$ Awareness of this possibility can sometimes provide a fairly simple explanation for unusual conditions.

LEON M GERLIS SIEW YEN HO ROBERT H ANDERSON Department of Paediatrics,
Royal Brompton National Heart and Lung Institute, Dovehouse Street,
London SWT3 $6 L Y$

1 Schulze-Neick I, Hausdorf G, Lange PE. Maldevelopment of conotruncal and aortopulmonary septum with absent left central pulmonary artery: anatomical and clinical pulmonary artery: anatomical and clinica

2 Gerlis LM, Dickinson DF, Wilson N, Gibbs JL. Persistent fifth aortic arch. A report of $\mathrm{JL}$. Persistent fifth aortic arch. A report of
two new cases and a review of the literature. two new cases and a review of
Int $\mathcal{F}$ Cardiol 1987;16:185-92.

3 Becker AE, Anderson RH. Cardiac pathology. Becker AE, Anderson RH. Cardiac pathology.
Edinburgh: Churchill Livingstone, 1983: Edinbu

4 Gerlis LM, Ho SY, Anderson RH, Da Costa $P$. Persistent fifth aortic arch-a great pretender: three new covert cases. Int $\mathcal{F}$ Cardiol 1989;23:239-47.

\begin{tabular}{c}
\hline BRITISH \\
CARDIAC \\
SOCIETY \\
NEWSLETTER \\
\hline
\end{tabular}

1994 Annual Meeting

Torquay and the Riviera Centre hosted our annual meeting this year from 17 to 19 May. Among the nearly 2000 registering were 364 members, 500 non-members, and 339 nurses. Unlike four years ago, when we were last in Torquay, the weather was not on our side, but many have commented favourably on the scientific sessions and exhibition. The affiliated groups made significant contributions to the programme, and it was a pleasure to have the British Society for Cardiovascular Research participating for the first time with well attended sessions. Overall 350 abstracts were presented, together with the two plenary sessions, six affiliated groups' meetings, the Thomas Lewis Lecture given by Peter Sleight, and the St Cyres Lecture given by Gunter Breithardt. Well attended programmes were held by the technicians and the nurses.

Two sessions that attracted widespread praise were the "judges' choice" sessions in which abstracts attracting the highest marks during the review process were put together irrespective of their category. There is still a demand for general sessions and the Programme Committee, chaired by Andrew Henderson, will be reviewing the structure of the annual meeting in the next few months. Moderated posters were judged to be successful despite some technical difficulties.

The Young Research Workers Prize was judged this year by Stuart Cobbe (chair), David Hearse, George Just, and Andrew Newby. The session was well attended and the judges' decision difficult. Our congratulations go to the winner Dr Barbara Casade for her contribution "Effect of vagal stimulation by transdermal scopolamine on exercise performance and $\mathbf{R}-\mathbf{R}$ interval variability in patients with chronic heart failure" and to the three runners up Dr R S More, Dr S A Thorne, and Dr D M Walker.

Council discussed the structure of the meeting and is considering reducing the number of simultaneous oral sessions and increasing the number of posters-with an increasing proportion of posters being moderated. It may be necessary to increase the rejection rate for submitted abstracts. Please write to John Cleland at 9 Fitzroy Square with any comments you have by 1 October 1994.

Next year's meeting is in Harrogate from 23 to 25 May and will include the first Paul Wood Lecture created by Council with members' support.

Training and Manpower Committee

Michael Webb-Peploe writes that "the proposed programme for post-Calman higher training in cardiology has now been discussed by:

- The Specialist Advisory Committee (SAC) in Cardiovascular Medicine to the Joint Colleges' Higher Medical Training (JCHMT)

The Training and Manpower Committee of the British Cardiac Society

The Council of the British Cardiac Society

It will now be submitted to the JCHMT for comment and (we hope) ratification at their next plenary meeting in November.

After a minimum of 2 years general professional training (at SHO level starting after full registration), candidates will be expected to have passed the MRCP examination. Non-UK candidates from other EU countries will have to provide evidence of equivalent knowledge and experience if they wish to train in the United Kingdom. Posts for specialist training in cardiology will be obtained through competitive interview by committees similar to the present registrar/senior registrar appointment committees. Specialist training will last for 6 years:

Phase 1: Basic cardiology and acute general medicine

Two years' training in clinical cardiology, coronary care, basic non-invasive investigations (ECG, echocardiography, exercise testing, ambulatory monitoring, nuclear cardiology), and basic invasive investigations (cardiac catheterisation, temporary and permanent pacing) with at least 60 nights of resident unselected take with continuing responsibility for patients admitted.

Phase 2: Basic cardiology in a specialist centre Three years' further training in clinical cardiology (including care of post-surgical patients) and in non-invasive and invasive investigations, with an introduction to interventional cardiology and electrophysiology.
Phases 1 and 2 make up 5 years. Included in these 5 years will be protected time for research equivalent to 1 year.

Phase 3: Either advanced training for 1 year in one of

Interventional cardiology, non-invasive investigations, electrophysiology and advanced pacing, adult congenital heart disease, or a year of research for academic trainees

Further training for a year in general internal medicine for those wishing to acquire dual certification in both cardiology and general internal medicine.

There will be a formal annual assessment of both trainee and training programme involving the trainee, his/her trainer, the postgraduate dean (or representative), and the trainee's "mentor" (a cardiologist from a neighbouring unit). The results of this assessment will be recorded in a training log book (a confidential document and the property of the trainee) and will have the aim of improving the performance of the trainee, and remedying any deficiencies in the training programme.

The need to match the supply of suitably trained cardiologists to the needs of district general hospitals and tertiary centres requiring subspecialty cardiological skills (for example-intervention and electrophysiology) will require a tight control of the number of trainees receiving sixth year advanced training in cardiological sub-specialties (for which there is a limited demand) if we are to avoid training people for non-existent jobs. The best method of achieving this has still to be determined.

On the initiative of the President, John Parker, an open session was organised during the recent British Cardiac Society Meeting in Torquay to discuss training and manpower issues with all interested parties. This was a success and it is intended to hold similar sessions at future British Cardiac Society meetings."

British Cardiovascular Intervention Society

Huon Gray writes: “After a successful winter scientific meeting in Manchester the first copy of a BCIS Newsletter appeared and was distributed to members. This covered the content of the meeting and provided additional information to members about future meetings. The second newsletter has just been distributed and covers the very successful Angioplasty '94 meeting which was held in London. This was a two day meeting, attracting several delegates and speakers from Europe and the United States, and was attended by more than 300 people. A computer based inter-active audience participation system was in operation during the two day meeting and allowed immediate feed-back from the audience in response to questions from the speakers and panellists. This proved very successful and feedback from the audience showed great support for a similar meeting next year. More recently BCIS held a short session at the British Cardiac Society Annual Meeting in Torquay on the subject of intracoronary stenting. The next BCIS meeting will be held in Cardiff on Friday, 30 September.

Membership of BCIS continues to rise and is now over 300. Most members are medically qualified but a substantial minor- 
ity are technicians, radiographers, nurses, and those from industry. Peter Hubner and Alan Mackintosh have recently stood down as council members of BCIS, having held the posts of honorary secretary and honorary treasurer since the start of BCIS in 1987 , and the Society owes a great debt of gratitude to them for all their hard work over the formative years. With the additional retirement of John Dyet from Council, three new Council members were required. After a ballot of the membership, Mark de Belder, Tony Gershlick, and Mike Norell were elected to council.

In other European countries some angioplasty equipment is resterilised and used more than once. This obviously reduces costs but, after correspondence with $\mathrm{Dr}$ Susanne Ludgate at the Department of Health, it was clear that such a practice cannot be supported in the United Kingdom. The Department of Health have made it clear that any piece of equipment marked "for single use only" must be used once only.

BCIS has been in correspondence with the medical representatives on the Department of Transport's Advisory Panel about the issue of how soon patients may drive after coronary angioplasty. BCIS had suggested that this be left to the discretion of the physician, but the Department of Transport thought that patients should be advised to wait for one week after angioplasty before they drive. It was stressed that this is a guideline rather than a legal requirement, but nevertheless all those involved with angioplasty should appreciate the existence of this guideline.

The issue of funding the audit of interventional procedures is being pursued with representatives of the Department of Health to see whether additional funding can be secured. The existing audit process will continue in the meantime, but it is hoped that it may be possible to introduce a more sophisticated system, allowing for risk stratification and more accurate data returns. Although the data are incomplete the total number of angioplasty procedures undertaken in the United Kingdom is likely to be a true reflection of activity and in 1992 stood at 11575 procedures, representing 203 angioplasties per million population. 1993 data are currently being collated.

BCIS continues to thrive and recent developments, such as the increasing use of intracoronary stents, make interventional cardiology a subspecialty of great interestat least to its enthusiasts"
Epidemiology and Prevention Committee: Action on Secondary Prevention by Intervention to Reduce Events (ASPIRE)

David Wood writes: "The Epidemiology and Prevention Committee is undertaking a national survey of specialist cardiac centres and district general hospitals to estimate the potential for reducing the risk of a further major ischaemic event in patients with coronary heart disease.

A sample of 12 specialist cardiac centres, one from each of the eight new regions in England, together with two centres in Scotland and one each in Wales and Northern Ireland has been identified. At the same time, one district general hospital served by each of the specialist centres has also been identified to complete the sampling frame of 24 hospitals to be included in the survey.

In the specialist cardiac centres two groups of patients will be surveyed: those who have just had their first elective percutaneous transluminal coronary angioplasty (PTCA), and those fwho have just had their first elective coronary artery bypass graft operation (CABG). In the district general hospitals the two groups of patients will consist of those admitted with a first acute myocardial infarction and patients admitted to the coronary care unit with acute coronary ischaemia but no evidence of infarction. Consecutive patients ( $\leqslant 7 \theta^{\prime}$ years) will be identified retrospectively from the relevant procedure and admission records for the period 1 January 1993 onwards. The sample will consist of a total of 100 patients in each hospital, weighted to give equal numbers of patients in each of the two eligible diagnostic groups as well as equal numbers of men and women.

A trained nurse at each of the centres will be responsible for data collection from hospital records, which will be supplemented with information recorded on general practitioner records for the same period to give a clinical picture of recorded care. The patients will also be invited for an interview at the hospital to establish the extent to which the identified modifiable risk factors are being managed in terms of lifestyle and medication.

The survey is being coordinated by the Department of Clinical Epidemiology (David Wood) at the National Heart and Lung Institute in collaboration with the Department of Medical Statistics (Simon Thompson) at the London School of Hygiene and Tropical Medicine with fund- ing provided by the British Cardiac Society from an educational grant received from Merck Sharp and Dohme."

\section{European Society of Cardiology}

Philip Poole-Wilson writes: "By the time you read this item the Berlin Congress will be upon us. This is a joint congress between the European Society of Cardiology and the International Society and Federation of Cardiology. Members of the British Cardiac Society have made a substantial contribution to the programme and to the organisation of the meeting. Voting will take place on the formation of a new Board, on some changes to the statutes, and on the creation of a new working group on heart failure. Maarten Simoons from Rotterdam is the new chairman of the Executive Scientific Committee. Suggestions for the congress in Amsterdam in August 1995 should be sent to him or to the chairman of a working group."

\section{Notice of meetings}

The Fifth European Meeting of the French Cardiac Society is being held in Paris on 12 to 14 January 1995 . This meeting, at which both English and French are official languages, always attracts a significant attendance from the United Kingdom. Details, including abstract forms, may be obtained from the Société Française de Cardiologie, 15 rue de Madrid, 75008 Paris.

The American College of Cardiology is sponsoring the Eighth Annual International Workshop on "Future directions in interventional cardiology" in Santa Barbara from 23 to 24 September 1994. Details from the American College of Cardiology (fax: 0101 301897 9745).

An international conference on intrinsic adaptive mechanisms during ischaemia and reperfusion is being organised at European Heart House in Nice from 6 to 8 October 1994. Details from Dr G Heyndricks, Universite Catholique de Louvain, Avenue Hypocrate 10, 1200 Brussels.

D JOHN PARKER

President, British Cardiac Society,

9 Fitzroy Square,

London W1P $5 A H$

\section{NOTICE}

The 1995 Annual Meeting of the British

Cardiac Society will take place at the

Conference Centre, Harrogate, West Yorkshire from 23 to 25 May. 